\author{
Д.А. Соловей \\ К.т.н., доцент кафедры строительных технологий, \\ ORCID ID: 0000-0002-0769-4063
}

Н.Ф. Соловей іинженер

ЈКН̈СА, г. Киев

\title{
УСТАНОВЛЕНИЕ ЗАВИСИМОСТИ СТОИМОСТИ СТРОИТЕЛЬНЫХ РАБОТ ОТ ВЛИЯНИЯ ФАКТОРА СТЕСНЕННОСТИ ПРИ РЕКОНСТРУКЦИИ ЗДАНИЙ
}

\begin{abstract}
Аннотация. Статья посвяцена исследованиям влияния условий стесненности на эффективность выполнения работ при реконструкции зданий. В статье приводится номенклатура основных составляющих фактора стесненности. Предложена методика формирования перечня дестабилизируюиих факторов и их

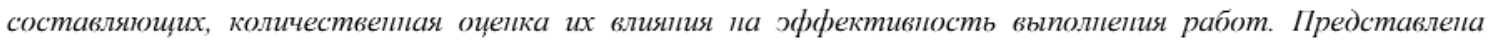
методика прогнозирования стоимости строительных работ в зависимости от степени влияния составляющих указанного фактора.

Ключевые слова: реконструкция, стесненные условия выполнения работ, технико-экономические показатели реконструкиии, эффективность строительных процессов.
\end{abstract}

\begin{abstract}
Актуальность темы. Наиболее характерной специфической особенностью процесса реконструкции зданий, находящихся в условиях городской застройки, является стесненность. Наличие определенных пространственных препятствий на строительной площадке и прилегающей к ней территории, мест размещения строительных машин, повышенную степень строительного, экологического, материального риска, меры безопасности для рабочих на строительной площадке и населения проживающего рядом характеризует условия стесненности. Стесненность не позволяет применять, в большинстве случаев, традиционную технологию и организацию выполнения работ, что влияет на показатели эффективности реконструкции в целом.

На этапе проведения инженерной подготовки объекта реконструкции, условия стесненности, как дестабилизирующий фактор, учитываются в организационно-технологических решениях проектно-технологической документации. Однако, степень влияния указанных условий на строительный процесс определить достаточно сложно, т.к. это обусловлено наличием большого количества составляющих, которые фактор стесненности в себя включает.

Достоверное определение техникоэкономических показателей реконструкции, с возможностью прогнозирования их изменения под влиянием составляющих фактора стесненности является актуальной задачей и требует дополнительных исследований.
\end{abstract}

Целью исследований является определение номенклатуры основных составляющих фактора стесненности, выявление количественных показателей и степени их влияния на эффективность выполнения работ. Это позволит, на подготовительном этапе, объективно оценить предполагаемые (плановые) показатели эффективности строительных работ с прогнозом их изменения под влиянием составляющих стесненности.

Обзор последних источников исследований и публикаций. Исследованием влияния условий реконструкции на технико-экономические показатели выполнения работ в условиях реконструкции зданий и сооружений посвящены труды известных ученых: Д.Ф. Гончаренко, В.В. Савйовского, И.В. ІШумакова, А.Ф. Осипова, Г.Н. Тонкачеева, А.И. Белоконя, Т.С. Кравчуновской, А.В. Радкевича, А.И. Менейлюка и др. Эти исследования находят свое отображение в научнотехнической [1-13] и нормативной литературе $[14,15]$. Однако, с учетом современного уровня механизации строительных процессов, новых технологий и подходов реконструкции, вопросы определения степени влияния указанных факторов на эффективность работ, требуют дополнительных исследований.

Основной материал и результаты. Для определения степени влияния условий стесненности на строительный процесс необходимо исследовать структуру данного дестабилизирующего фактора и определить номенклатуру его составляющих. Для этого автором был проведен анализ проектно- 
технологической и сметной документации на ряде объектов реконструкции, находяшихся в сложных условиях городской застройки, характеризующихся стесненностью.

В процессе анализа была обработана, сгруппирована и систематизирована информация о принятых решениях в проектно-технологической документации, а также о сметной стоимости объектов. В результате проведенного анализа был определен перечень основных составляющих исследуемого фактора:

$X_{I}$ - ограничение размещения на территории строительной площадки грузоподъемного строительного оборудования и других крупногабаритных строительных машин;

$X_{2}$ - сложность доставки строительных конструкций и материалов на объект;

$X_{3}$ - ограничение размещения на территории строительной площадки открытых и закрытых складов, площадок укрупнительной сборки конструкций;

$X_{4}$ - ограничение беспрепятственного движения, маневрирования во время работы строительных машин и оборудования и наличие места их длительной стоянки; невозможность устройства объездных дорог;

$X_{5}$ - ограничение рабочих зон строительных машин на территории строительной площадки;

$X_{6}$ - ограничение размещения на территории строительной плошадки административно-бытовых помещений.

Для оценки важности и частоты повторяемости исследуемых составляюших был использован метод экспертных оценок. В качестве экспертных групп были привлечены специалисты учебных и научноисследовательских учреждений, инженеры проектных организаций и инженерно-технические работники строительных предприятий.

Группы экспертов выполнили ранжирование отобранных составляющих по степени их влияния на технико-экономические показатели. Составляющая, имеющая наиболее значительное влияние, имела ранг 6, а наименее значительное ранг 1. Оценки экспертов распределились следующим образом (табл.1):

Таблицуа 1. Ранжирование составляюичих фактора стесненности по оченкам экспертов

\begin{tabular}{|c|c|c|c|c|c|c|}
\hline $\begin{array}{c}\text { Составляющая } \\
\text { фактора }\end{array}$ & $X_{l}$ & $X_{2}$ & $X_{3}$ & $X_{4}$ & $X_{5}$ & $X_{6}$ \\
\hline Средний ранг & 5,3 & 4,7 & 3,4 & 3,2 & 2,3 & 2,1 \\
\hline Ранг & 6 & 5 & 4 & 3 & 2 & 1 \\
\hline
\end{tabular}

Для оценки согласованности мнения экспертов применим математический метод и рассчитаем коэффициент конкордации Кендалла (коэффициент множественной ранговой корреляции) по формуле:

$\mathrm{W}=\frac{12 \times \mathrm{S}}{\mathrm{m}^{2} \times\left(\mathrm{n}^{2}-\mathrm{n}\right)}=\frac{12 \times 818}{10^{2} \times\left(6^{2}-6\right)}=0.467$,

где $m$ - число экспертов, $n$ - число оцениваемых факторов, $S$ - сумма квадратов разностей рангов (отклонений от среднего). Расчет показал, что коэффициент конкордации $\mathrm{W}=0,467$, что показывает слабую степень согласованности мнений экспертов, т.е. величина не случайная, а потому полученные результаты имеют смысл и могут использоваться в дальнейших исследованиях.

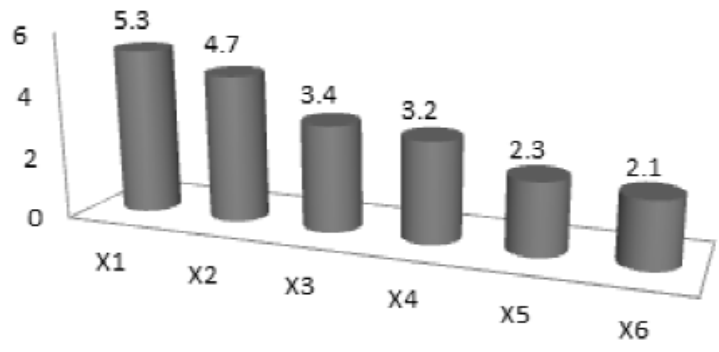

Рис. 1 Диаграмма рангов

Результаты экспертных данных обработаны методом ранговой корреляции Спирмена. Ранговый коэффициент корреляции определен по формуле:

$$
\mathrm{P}=1-\frac{6 \times \sum\left(\mathrm{D}^{2}\right)}{\mathrm{n} \times\left(\mathrm{n}^{2}-1\right)}=\frac{6 \times 12}{6 \times(6 \times 6-1)}=0.34
$$

где $n$ - количество ранжируемых признаков (исследуемых составляющих $n=6$ ); $D$ - разность между рангами по двум переменным для $i$-ой составляющей фактора стесненности; $\sum D^{2}$ - сумма квадратов разностей рангов.

Нахождение уровней значимости в таблице критических значений коэффициента корреляции рангов Спирмена осуществляется по числу $n$, т. е. по числу исследуемых составляющих фактора. Полученный коэффициент корреляции ниже критического значения ( 0.85 для $P \leq 0.05$ ) для уровня значимости в $5 \%$. Следовательно, можно утверждать, что правильность обработки результатов информации об исследуемых объектах и итоговые экспертные оценки связаны положительной корреляционной зависимостью.

При рассмотрении принятых организационнотехнологических решений на объектах реконструкции внимание уделялось степени влияния составляющих фактора стесненности на технологию, организацию и стоимость выполнения работ, с целью анализа изменения показателей эффективности выполнения работ с учетом влияния составляющих $\left(X_{l} \ldots X_{6}\right)$ фактора стесненности. Количество выборки объектов (табл.2) устанавливалось с целью обеспечения достоверности результатов. 
Таблица 2. Таблица коэффициентов степени влияния составляющих фактора стесненности

\begin{tabular}{|c|c|c|c|c|c|c|}
\hline \multirow{2}{*}{$\begin{array}{c}\text { № объекта } \\
\text { реконструкции }\end{array}$} & \multicolumn{6}{|c|}{ Составляюоая фактора стесненности } \\
\hline & $\mathrm{X}_{1}$ & $\mathrm{X}_{2}$ & $\mathrm{X}_{3}$ & $\mathrm{X}_{4}$ & $\mathrm{X}_{5}$ & $\mathrm{X}_{6}$ \\
\hline 1 & 1.05 & 1.04 & 1.02 & 1.015 & 1.01 & 1.01 \\
\hline 2 & 1.045 & 1.01 & 1.045 & 1.03 & 1 & 1.012 \\
\hline 3 & 1.045 & 1.045 & 1.035 & 1.034 & 1.015 & 1.01 \\
\hline 4 & 1.035 & 1.05 & 1.03 & 1.02 & 1 & 1 \\
\hline 5 & 1.025 & 1.023 & 1.025 & 1.01 & 1 & 1.015 \\
\hline 6 & 1.05 & 1.037 & 1.035 & 1.026 & 1.01 & 1.006 \\
\hline 7 & 1.035 & 1.045 & 1.04 & 1.04 & 1.009 & 1.01 \\
\hline 8 & 1.02 & 1 & 1.01 & 1.01 & 1.015 & 1.012 \\
\hline 9 & 1.04 & 1.05 & 1.035 & 1.03 & 1.01 & 1.015 \\
\hline 10 & 1.05 & 1.035 & 1.03 & 1.045 & 1 & 1.01 \\
\hline 11 & 1.035 & 1.01 & 1.01 & 1.01 & 1.01 & 1 \\
\hline 12 & 1.05 & 1.05 & 1.044 & 1.033 & 1 & 1.006 \\
\hline 13 & 1.03 & 1.02 & 1.005 & 1.01 & 1 & 1 \\
\hline 14 & 1.045 & 1.01 & 1.015 & 1.04 & 1.01 & 1.005 \\
\hline 15 & 1.05 & 1.025 & 1.022 & 1.041 & 1.015 & 1.01 \\
\hline 16 & 1.03 & 1.02 & 1 & 1.025 & 1 & 1 \\
\hline 17 & 1.035 & 1.042 & 1.01 & 1.01 & 1.005 & 1 \\
\hline 18 & 1.04 & 1.06 & 1.035 & 1.025 & 1 & 1 \\
\hline 19 & 1.062 & 1.034 & 1.03 & 1.037 & 1.01 & 1.01 \\
\hline 20 & 1.03 & 1.01 & 1.015 & 1.015 & 1 & 1 \\
\hline 21 & 1.04 & 1.025 & 1.02 & 1.01 & 1.015 & 1.01 \\
\hline 22 & 1.05 & 1.05 & 1.03 & 1.035 & 1.01 & 1 \\
\hline 23 & 1.025 & 1.02 & 1.015 & 1.01 & 1.01 & 1.01 \\
\hline 24 & 1.056 & 1.05 & 1.025 & 1.04 & 1.005 & 1.006 \\
\hline 25 & 1.04 & 1.04 & 1.025 & 1.025 & 1 & 1.01 \\
\hline 26 & 1.025 & 1.035 & 1.03 & 1.02 & 1.01 & 1.015 \\
\hline 27 & 1.045 & 1.05 & 1.031 & 1.04 & 1.015 & 1 \\
\hline 28 & 1.04 & 1.025 & 1.026 & 1 & 1.01 & 1.02 \\
\hline 29 & 1.048 & 1.036 & 1.042 & 1.044 & 1.015 & 1.01 \\
\hline 30 & 1.035 & 1.02 & 1.025 & 1.01 & 1 & 1 \\
\hline 31 & 1.055 & 1.04 & 1.035 & 1.02 & 1.013 & 1.015 \\
\hline 32 & 1.025 & 1.02 & 1.01 & 1 & 1 & 1 \\
\hline 33 & 1.05 & 1.035 & 1.04 & 1.045 & 1.01 & 1.01 \\
\hline 34 & 1.045 & 1.028 & 1.032 & 1.034 & 1.015 & 1.01 \\
\hline 35 & 1.04 & 1.03 & 1.025 & 1.015 & 1.01 & 1.01 \\
\hline 36 & 1.03 & 1.04 & 1.026 & 1 & 1 & 1.01 \\
\hline 37 & 1.055 & 1.01 & 1.014 & 1.04 & 1.009 & 1.006 \\
\hline 38 & 1.065 & 1.04 & 1.031 & 1.03 & 1.01 & 1.008 \\
\hline 39 & 1.045 & 1.035 & 1.018 & 1.01 & 1.015 & 1 \\
\hline 40 & 1.06 & 1.065 & 1.02 & 1.023 & 1.01 & 1.01 \\
\hline $\begin{array}{c}\text { Средний } \mathbf{k} \text { по } \\
\mathbf{i}-и ̆ \text { оставляющей }\end{array}$ & 1.042 & 1.033 & 1.025 & 1.024 & 1.008 & 1.007 \\
\hline
\end{tabular}

Для определения степени влияния каждой из составляющих фактора стесненности на стоимость выполнения работ автором был предложен вариант вероятной оценки показателя количественной меры каждой из них. В качестве таких показателей, соответствующих каждой составляющей $X_{i}$ были приняты безразмерные коэффициенты учитывающие степень увеличения стоимости $k_{i}$ по сравнению с условиями, при которых указанная составляющая фактора стесненности не оказывает негативного влияния на эффективность работ. Для количественной оценки степени влияния каждой из составляющих предложено общее выражение:

$$
k_{\mathrm{i}}=1+\frac{\mathrm{C}_{\mathrm{i}}}{\mathrm{C}_{\text {пр. }}}
$$

где $\mathrm{C}_{\mathrm{i}}$ - дополнительные финансовые затраты на выполнение работ при влиянии $i$-й составляющей;

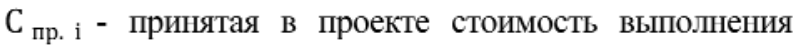
работ в условиях, при которых $i$-я составляющая отсутствует, т.е. не оказывает негативного влияния. 
В случае получение величины коэффициента $k_{i}>1$ указанная составляющая фактора оказывает влияние на стоимость работ, а при $k_{i}=1\left(\mathrm{C}_{\mathrm{i}}=0\right)$ составляющая не оказывает негативного влияния.

Данные из табл. 2 показывают полученные по каждому из исследованных объектов коэффициенты $\left(k_{l} \ldots k_{6}\right)$ учитывающие степень увеличения финансовых затрат при наличии составляюших фактора стесненности $\left(X_{l} \ldots X_{6}\right)$, что указывает на прямо пропорциональное негативное воздействие каждой из указанных составляющих на себестоимость.

Из таблицы видно, что наибольшие показатели, которые существенно влияют на себестоимость реконструкции имеют следующие составляющие стесненности: нерациональное размещение и использование грузоподъемного оборудования или отсутствие возможности его установки $\left(X_{l}\right)$; сложность доставки строительных конструкций и материалов на объект $\left(X_{2}\right)$; отсутствие на территории строительной площадки мест для складов и площадок укрупнительной сборки конструкций $\left(X_{3}\right)$; затруднение при перемещении во время работы строительных машин по строительной площадке; отсутствие объездных дорог и подъездов к площадке $\left(X_{4}\right)$. Исследования показывают, что составляющие $\left(X_{5}\right.$ и $\left.X_{6}\right)$ фактора стесненности не существенны, поэтому ими можно пренебречь.

При анализе значений полученных коэффициентов, для определения достоверности, был использован метод оценки значимости различий средних величин ( $t$-критерий Стьюдента). В исследовании данный метод автором был использован как для варианта сравнении связных и равных по численности выборок (совокупностей). В случае связных выборок с равным числом измерений в каждой можно использовать более простую формулу $\mathrm{t}$ - критерия Стьюдента:

$$
\begin{gathered}
t_{\text {эмп }}=\frac{\bar{d}}{S_{d}}=\frac{0,146}{0,07}=2,08 \\
\bar{d}=\frac{\sum_{40}^{1} d_{i}}{n}=\frac{\sum_{40}^{1}\left(x_{i}-y_{i}\right)}{n}=\frac{45,87-40}{40}=0,146 \\
S_{d}=\sqrt{\frac{\sum_{40}^{1} d_{i}-\left(\sqrt{\left.d_{i}^{2}\right) / n}\right.}{n \times p}}=\sqrt{\frac{0,94-(5,87 \times 5,87) / 40}{40 \times(40-1)}}=0,07 \\
\text { где } d_{i}=\left(x_{i}-y_{i}\right) \quad-\quad \text { разности между }
\end{gathered}
$$
соответствующими значениями $\boldsymbol{x}$ (npu $\left.k_{c m}>1\right)$ и $\boldsymbol{y}$ ( $\left.п р и k_{c m}=1\right)$, а $\bar{d}$ среднее этих разностей; $p=n-1$ число степеней свободы $(p=40-I=39)$.

Критические значения $\boldsymbol{t}$-критерия Стьюдента при коэффициенте свободы $\mathrm{p}=40$ равны: 2.02 для $\mathrm{P}<$ $0.05 ; 2,70$ для $\mathrm{P}<0.01$. Полученное значение t- критерия $\mathrm{p}=2,08$ меньше критического, т.е. можно сделать вывод о том, что наблюдаемые различия статистически не значимы (уровень значимости около 5\%) и значения коэффициентов составляющих фактора стесненности можно использовать для дальнейших исследований.

Для объективной оценки исследуемого показателя стоимости работ и возможности его прогнозирования с достаточной точностью, на основе полученных коэффициентов влияния, была составлена дескриптивная экономикостатистическая модель. Данная модель отражает влияние рассматриваемых составляющих фактора стесненности на показатель стоимости работ. Для описания модели принято линейное уравнение (парная регрессия):

$$
Y_{i}=a+b \times k_{\mathrm{i}},
$$

где $a-$ нормативное значение усредненного показателя стоимости выполнения работ; $k_{i}-$ среднее численное значение коэффициента влияния по $i$-й составляющей фактора стесненности.

Параметры уравнения линейной регрессии находим методом наименьших квадратов. Получаем уравнения парной регрессии, характеризующие зависимость стоимости работ от величины коэффициента влияния составляющей фактора стесненности:

$$
\begin{aligned}
& Y_{\mathrm{X} 1}=4361+3872 \times k_{1} ; \\
& Y_{\mathrm{X} 2}=3940+4136 \times k_{2} ; \\
& Y_{\mathrm{X} 3}=3180+4865 \times k_{3} ; \\
& Y_{\mathrm{X} 4}=3504+4560 \times k_{2} .
\end{aligned}
$$

Подставляя в уравнение коэффициенты строим график зависимости, рис.2. Множество значений (точек на графике) формирует кривые, которые можно аппроксимировать к прямым. Для оценки надежности полученного уравнения регрессии и проверки значимости регрессионной модели автором был использован $\mathbf{F - к р и т е р и и ̆ ~ Ф и ш е р а ~}$ (метод оценки распределений). Проверка адекватности модели, подтвердила, что модель соответствует реальным показателям стоимости объектов реконструкции, что дает возможность дальнейшей работы с полученной моделью.

На основании проведенных исследований, обеспечивающих репрезентативность результатов, была построена графическая зависимость (рис.2), которая показывает: чем больше угол наклона построенной прямой к линии абсцисс, тем больший удельный вес той или иной составляющей фактора стесненности, т.е. тем больше влияние коэффициента на себестоимость работ. 


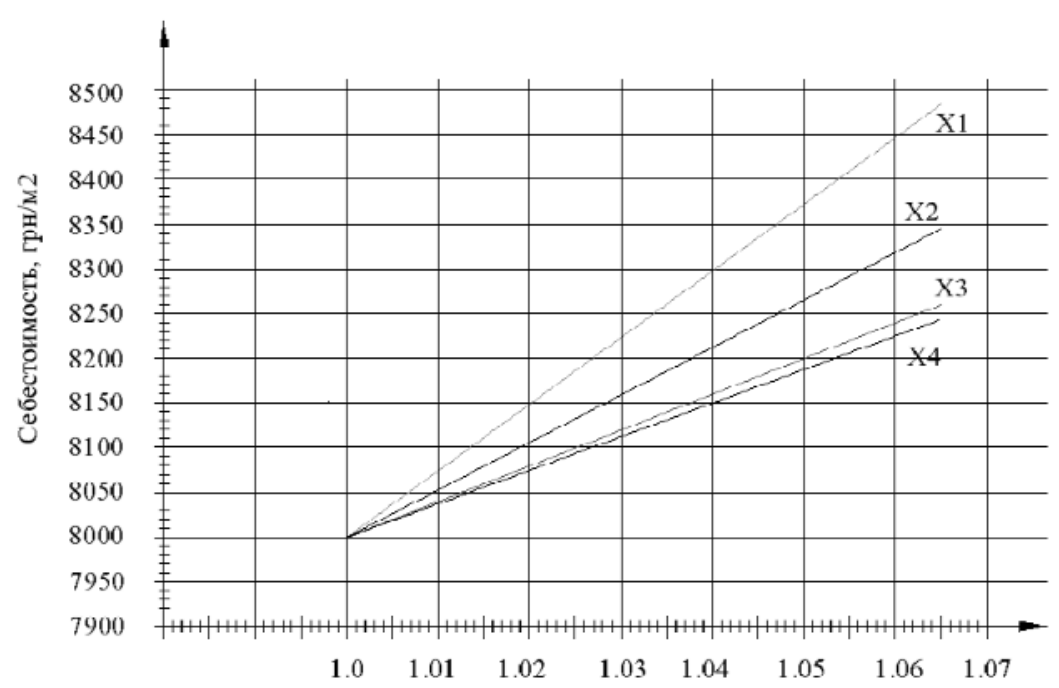

Значения составляющих фактора стесненности X1-X4

Рис.2 График зависимости стоимости строительных процессов от влияпия составляпоцих фактора стесненности

\section{Выводы и рекомендации.}

В процессе анализа проектно-технологической и сметной документации объектов реконструкции, а также результатов экспертных оценок, определена номенклатура основных составляющих фактора стесненности.

Установлено что наиболее существенное влияние составляющих стесненности на техникоэкономические показатели реконструкции оказывают следующие: отсутствие возможности установки или рационального использования грузоподъемного оборудования; сложность доставки конструкций и материалов на объект; отсутствие мест для складов и площадок укрупнительной сборки конструкций; затруднение перемещения строительных машин по строительной площадке, отсутствие объездных дорог и подъездов.
Для определения количественных показателей степени влияния, составляющих фактора стесненности на эффективность выполнения работ предложена методика на основе математический модели, которая адекватна реальным условиям реконструкции здания. С помощью этой методики можно оценивать не только степень отдельного или комплексного (группового) влияния указанных составляющих, а и объективно оценивать плановую стоимость строительных работ и прогнозировать возможное ее изменения в зависимости от влияния каждой из составляющих.

Данная методика может применяться на этапе инженерной подготовки реконструкции, как при разработке инвестиционных проектов, ПОС, ППР, так и при анализе конкретных ситуаций, непосредственно на объекте реконструкции.

\section{Juтература}

1. Беляков Ю.І. Строительные работы при реконструкции предприятий. / Беляков Ю.И., Резуник А.В., Федосенко Н.Ф. М.: Стройиздат. - 1986. - С.224.

2. Шагин А. Л. Реконструкиия зданий и сооружений. / Шагин А. Л., Бондаренко Ю. В., Гончаренко Д. Ф., Гончаров В. Б.- М.: Высш. шк. -1991. - C. 352

3. Осипов А.Ф. Особенности объемно-планировочных и конструктивных характеристик реконструируемьх жилых зданий г. Киева / А. Ф. Осипов, С. Ф. Акимов // Строительство и техногенная безопасность. - 2002.- Bып.6.- C.260-265. 4. Савйовський В.В. Реконструкиія будівель і споруд. / В.В. Савйовский - К.: Лира-К, 2018. - С.315

5. Савйовский В.В. Технология реконструкии. / В.В. Савйовский-Харьков.: "Основа", 1997. - 254 c.

6. Гончаренко Д.Ф. Эксплуатация, ремонт и восстановление трубопроводов водоснабжения. / Гончаренко Д.Ф., Хайнрих Вевелер, Алейникова А.И.- Х. :"Раритеты Украинь", 2015. -С.263

7. Соловей Д. А. Расчетное обоснование вариантного проектирования технологии строительства в условиях плотной городской застройки / Д. А. Соловей, А. П. Броневицький. // Збірник наукових праць. Серія: галузеве машинобудування, будівнищтво. ПолтНТУ.. - 2015. - №3. - С. 117-125.

8. Соловей Д. А. Особенности монтажа металлических конструкций каркаса здания в стесненных условиях. / Соловей Д. А., Броневищький А.П. // Містобудування та територіальне планування. Наук.-техн. збірник. Вип. 55. К.: Міносвіти Украӥни, КНУБА 2015, С. $386-392$

9. Соловей Д. А. Технологические особенности монтажно-демонтажных работ в стесненных условиях реконструкции. /Соловей Д. А., Чертков О.Ю. // Містобудування та територіальне планування. Наук.-техн. збірник. Вип.68. - К.: Міносвіти Украйни, КНУБА.. - 2018. - №68. - С. 365-373

10. Савйовский В. В. Влияние условий реконструкиии на технико-экономические показатели строительномонтажных работ / Савйовский В. В., Соловей Д. А.. // Науковий вісник будівництва. Харків: ХНУБА.. - 2016. №85. - C. 300-304.

11. Исаханов Г.В. Основы научных исследований в строчтельстве. / Исаханов Г.В. - К.: Вища школа, 1985 - 142 с. 
12. Крутов В.И. Основы научных исследований. / Крутов В.И., Грушко И.М., Попов В.В. и др. // Учеб. для техн. вузов - М.: Высш.шк., 1989. - 400 c.

13. Сидоренко Е. В. Методы математической обработки в психологии. / Сидоренко Е. В. // Санкт-Петербург: ООО "Речь", 2001, c.52.

14. ДБН В.1.2-12-2008. СНББ. Будівництво в умовах ущільненої забудови. Вимоги безпеки. - К.: Мінрегіонбуд України, 2008. - 36 с.

15. ДБН В.3.2.-2-2009. Реконструкція і капітальний ремонт. - К.: Мінрегіонбуд України, 2009. - 16 с.

\title{
References
}

1. Belyakov Yu.I. Rezunik A.V., Fedosenko N.F. (1986). Construction work during the reconstruction of enterprises. Moscow, Russia: Stroyizdat, 224.

2. Shagin A. L., Bondarenko Yu. V., Goncharenko D.F., Goncharov V. B. (1991). Reconstruction of buildings and structures. Moscow, Russia: Higher. school, 352.

3. Osipov A.F. (2002). Features of space-planning and structural characteristics of reconstructed residential buildings in Kiev / A.F. Osipov, S.F. Akimov // Construction and industrial safety, Issue 6, P.260-265.

4. Savyousky V.V. (2018). Reconstruction of buildings and structures. - Kyiv, Ukraine: Lira-K, 315.

5. Savyovsky V.V. (1997). Reconstruction technology. Kharkov, Ukraine: Osnova, 254.

6. Goncharenko D.F., Aleinikova A.I., Heinrich Weveler. (2015). Operation, repair and restoration of water supply pipelines. Kharkov, Ukraine: Rariteti Ukraine, 263.

7. Solovey D.A. (2015). Calculation substantiation of variant design of construction technology in the conditions of dense urban development / D.A. Solovey, A.P. Bronevitsky // Collection of scientific works. Series: industry engineering; construction. PoltNTU, Issue 6, 117-125.

8. Solovey D.A. (2015). Features of installation of metal structures of a skeleton of a building in narrow conditions. / Solovey D.A., Bronevitsky A.P. // Urban planning and territorial planning. Scientific-technical collection. Issue 55, P.386-392

9. Solovey D.A. (2018). Technological features of assembly and dismantling works in the constrained conditions of reconstruction. / Solovey D.A., Chertkov O.Yu. // Urban planning and territorial planning. Scientific-technical collection. Issue 68, P.365-373.

10. Savyozsky V.V. (2016). Influence of reconstruction conditions on the technical and economic indicators of construction and installation works / Savyovsky V.V., Solovey D.A. // Naukovy visnik Budivnitsva. Issue 85, P.300-304.

11. Isakhanov G.V. (1985). Fundamentals of scientific research in construction. Kyiv, Ukraine: Higher. school, 142.

12. Krutov V.I., Grushko I.M., Popov V.V. (1989). Fundamentals of scientific research. Textbook for tech. universities. Moscow, Russia: Higher. school, 400.

13. Sidorenko E. V. (2001). Methods of mathematical processing in psychology. St. Petersburg, Russia:: Rech LLC, 52.

14. Construction in the conditions of compacted development. Security requirements: DBN B.1.2-12-2008. - (Effective from 01.01.2009). - Keiv: Ministry of Regional Building of Ukraine, 2008. - 36 p. - (National standard of Ukraine).

15. Reconstruction and major repairs: DBN B.3.2.-2-2009. - (Effective from 01.01.2010). - Keiv: Ministry of Regional Building of Ukraine, 2009. - 16 p. - (National standard of Ukraine).

Д.А. Соловей, к.т.н., доцент, ORCID ID: 0000-0002-0769-4063;

Н.Ф. Соловей, інженер, Київський національний університет будівництва та архітектури, м. Київ,

\section{ВСТАНОВЛЕННЯ ЗАЛЕЖНОСТІ ВАРТОСТІ БУДІВЕЛЬНИХ РОБІТ ВІД ВПЛИВУ ФАКТОРУ УЩЛЬНЕНОСТІ ПРИ РЕКОНСТРУКЦІї БУДІВЕЛЬ}

\begin{abstract}
Анотація. Стаття присвячена дослідженню впливу умов обмеженості на ефективність виконання робіт при реконструкиї будівель. У статті запропонована методика формування переліку дестабілізуючих факторів і їх складових, кількісна оцінка їх впливу на ефективність виконання робіт, представлена методика прогнозування вартості будівельних робіт в залежності від ступеня впливу складових зазначеного фактора.

у процесі аналізу була оброблена, згрупована і систематизована інформація про прийняті рішення в проектно-технологічній документації, а також про кошторисну вартість об'єктів.

Для визначення ступеня впливу кожної зі складових фактора обмеженості на вартість виконання робіт було запропоновано варіант можливої оцінки показника кількісної міри кожної з них.

Для об'єктивної оцінки досліджуваного показника вартості робіт $і$ можливості його прогнозування з достатньою точністю, на основі отриманих коефімієнтів впливу, була складена дескриптивна економіко-статистична модель. Дана модель відображає вплив розглянутих складових факторів обмеженості на показник вартості робіт.

На підставі проведених досліджень, які забезпечують репрезентативність результатів, була побудована графічна залежність, яка показує: чим більше кут нахилу побудованої прямої до лінії абсиис, тим більша питома вага тієі чи іншої складової фактора обмеженості, тобто тим більше вплив коефіцієнта на собівартість робіт.

У процесі аналізу проектно-технологічної та кошторисної документації об'єктів реконструкиїі, а також результатів експертних оцінок визначено номенклатуру основних складових фактора обмеженості.

Для визначення кількісних показників ступеня впливу, що становлять фактори обмеженості на ефективність виконання робіт, запропонована методика на основі математичної моделі, яка адекватна реальним умовам реконструкцї будівлі.
\end{abstract}


Дана методика може застосовуватися на етапі інженерної підготовки реконструкцї̈, як при розробиі інвестиційних проектів, ПОС, ППР, так $і$ при аналізі конкретних ситуацій, безпосередньо на об'єкті реконструкиї.

Ключові слова: реконструкція, обмежені умови виконання робіт, техніко-економічні показники реконструкиї, ефективність будівельних процесів.

D. Solovey, ORCID: 0000-0002-0769-4063, Cand. tech Sciences, Associate Professor;

N. Solovey, engineer. Kyiv National University of Construction and Architecture, Kyiv

\section{ESTABLISHING THE DEPENDENCE OF THE COST OF CONSTRUCTION WORKS ON THE INFLUENCE OF THE CAPACITY FACTOR DURING RECONSTRUCTION OF BUILDINGS}

Annotation. The article is devoted to studies of the influence of constraint conditions on the efficiency of work during the reconstruction of buildings. The article provides a nomenclature of the main components of the constraint factor. A technique for forming a list of destabilizing factors and their components, a quantitative assessment of their impact on the efficiency of work is proposed. A method for predicting the cost of construction work is presented, depending on the degree of influence of the components of this factor.

Key words: reconstruction, cramped working conditions, technical and economic indicators of reconstruction, the effectiveness of construction processes.

Науково-дослідний інститут будівельного виробництва (НДІБВ)

\section{Пропонуємо нормативну та методичну літературу:}

\begin{tabular}{|c|l|c|c|}
\hline № & \multicolumn{1}{|c|}{ Назва } & Мова & $\begin{array}{c}\text { Ціна за } \\
\text { примірник }\end{array}$ \\
\hline 1 & $\begin{array}{l}\text { „Методичні рекомендації визначення вартості робіт 3 } \\
\text { обстеження, оцінки технічного стану і паспортизації будівель і } \\
\text { споруд” }\end{array}$ & Укр. & 120,00 \\
\hline 2 & $\begin{array}{l}\text { ДБНУ „Ремонт і підсилення несучих та огороджувальних } \\
\text { будівельних конструкцій і основ промислових будинків та } \\
\text { споруд” }\end{array}$ & Укр./pус. & 250,00 \\
\hline 3 & $\begin{array}{l}\text { «Методичні рекомендації з виконання геодезичних робіт у } \\
\text { будівництві» }\end{array}$ & Укр. & 120,00 \\
\hline 4 & $\begin{array}{l}\text { «Типові норми чисельності працюючих на підприємствах } \\
\text { комунальної теплоенергетики» }\end{array}$ & Укр. & 700,00 \\
\hline 5 & $\begin{array}{l}\text { «Посібник з питань здійснення державного архітектурно- } \\
\text { будівельного контролю» }\end{array}$ & Укр. & 360,00 \\
\hline 6 & $\begin{array}{l}\text { „Нормативні документи з питань обстежень, паспортизації, } \\
\text { безпечної та надійної експлуатації виробничих будівель і } \\
\text { споруд” }\end{array}$ & Укр. & 270,00 \\
\hline 7 & $\begin{array}{l}\text { «Гідроізоляція будівель і споруд. Сучасні вимоги» } \\
\text { «кор. }\end{array}$ & 96,00 \\
\hline 8 & $\begin{array}{l}\text { Науково-технічний супровід реконструкції Національного } \\
\text { спортивного комплексу «Олімпійський» в Києві }\end{array}$ & Укр. & 300,00 \\
\hline
\end{tabular}

